Article

\title{
Fortification and Elevated Alcohol Concentration Affect the Concentration of Rotundone and Volatiles in Vitis vinifera cv. Shiraz Wine
}

\author{
Pangzhen Zhang ${ }^{*}{ }^{\dagger}$, Fangping Luo ${ }^{\dagger}$ and Kate Howell \\ School of Agriculture and Food, University of Melbourne, Parkville, Vic 3010, Australia; \\ fangpingl@student.unimelb.edu.au (F.L.); khowell@unimelb.edu.au (K.H.) \\ * Correspondence: pangzhen.zhang@unimelb.edu.au; Tel.: +61-42-589-6788 \\ t These authors contributed equally to this work.
}

Received: 27 May 2017; Accepted: 23 June 2017; Published: 27 June 2017

\begin{abstract}
Rotundone is a key aromatic compound for cool-climate Shiraz. This compound is produced in the skin of grape berries and extracted into wine during fermentation. This project investigated the influence of fermentation techniques on the concentration of rotundone in the resultant wine. Wine was fortified with ethanol and sucrose on the 1st and 5th days of fermentation and rotundone, volatile aroma compounds and colour were assessed in the resultant wine. The relationship between the concentration of rotundone and alcoholic strength during fermentation process was also investigated. Wine alcoholic strength and skin-wine contact time were two factors affecting rotundone extraction rate from grapes into wine. Fortification significantly enhanced rotundone extraction rate, and improved wine colour and phenolics and affects the concentration of ethyl acetate, 3-methylbutyl acetate, ethyl butanoate, ethyl hexanoate, ethyl octanoate, methyl nonanoate, isopentanol and phenylethyl alcohol in the resultant wine. Understanding how ethanol produced during fermentation can change the extraction of skin-bound aroma compounds and the colour and flavour of wine allows greater control of fermentation parameters to produce quality wine.
\end{abstract}

Keywords: wine fortification; alcohol content; rotundone; Shiraz; wine; aroma profile

\section{Introduction}

There are numerous compounds in grape berries forming a complex mixture that affect the aroma and flavour in wine [1]. Some of these compounds, in particular monoterpenes, are hydrolysed from an odourless glycosidic form into active aromatic form during winemaking and/or storage [2]. Rotundone, an oxygenated bicyclic sesquiterpene in grape berries, is unlikely to undergo modification during fermentation, and remains chemically unchanged from the grape to the wine [3-5]. Rotundone is responsible for the attractive "pepper" character in grape berries and wine, and is especially important for cool-climate Shiraz (Syrah) [6-8]. It is possible to manipulate the concentration of this compound in wine by increasing rotundone production in grape berries [8-19]. Approximately $10 \%$ of the rotundone in grape skins is extracted into the grape berries during fermentation, regardless of starting concentration, so any manipulation that increases the amount of rotundone in grapes will be reflected by an increase in wine.

Understanding how rotundone is produced in grape berries allows winegrowers to produce higher quality wine. It is clear that climate and weather variables are important as rotundone has been observed in Shiraz wine produced from cool-climate wine regions [4]. Large variations in the concentration of rotundone have been observed within vineyards, between vines and within bunch regions, with more rotundone produced in areas having a southerly aspect, higher canopy cover and shading of bunches [16]. These factors explain how lower bunch zone air temperature, lower berry 
surface temperature, less direct solar exposure and higher precipitation are associated with elevated rotundone production $[8,10,16]$. Higher irrigation together with on-vine drying has been proven as an effective viticultural technique to improve rotundone concentration in the resultant wine [11].

The stage of grapevine maturity affects rotundone with the highest concentration observed at fruit-set and harvest $[17,18]$. The concentration of rotundone in grape berries increases gradually after veraison $[8,10]$ and applying a plant growth regulator to grapevine to manipulate grapevine phenological development delays grape ripening and harvest, and therefore increases the concentration of rotundone in grape berries [9]. Higher grapevine vigour is associated with more shading in the fruit zone and higher leaf to fruit ratio. The concentration of rotundone in grapevine leaves and the potential translocation of rotundone between leaves and fruit were investigated, and it was reported that although there were high concentrations of rotundone in grapevine leaves, petiole, and peduncle, there was no translocation between different grapevine organs and grape berries [19].

The capacity of rotundone production varies amongst different grapevine clones, and is associated with pest/disease stress [4,12]. Under similar growing conditions, Shiraz 2626 clone and Duras 554 and 654 clones have been identified to produce relatively higher concentration of rotundone $[4,12]$. Many terpenes are considered as herbivore-induced plant volatiles, and are produced by grapevines as defensive metabolites in response to pests. However, no elevation in the concentration of rotundone was observed when feeding grapevine leaves with larvae of the light brown apple moth [19]. On the other hand, disease has been associated with rotundone production, with more rotundone observed in Duras grapes with higher severity of powdery mildew [12].

The influence of winemaking practice on the concentration of rotundone in wine is not well understood. Rotundone mainly accumulates in the first five days of primary fermentation in Shiraz [5,20]. Caputi et al. [21] reported the low extraction rate of rotundone during the fermentation process of Vespolina grapes (less than 10\% recovered in wine). Addition of grape leaves and stems into fermentation tanks [22] gives a 6-fold increase in the concentration of rotundone, which may be explained by the high rotundone content in non-grape materials [19]. A shorter time of contact between grape skins and juice leads to a significantly lower concentration of rotundone in thermos-vinification and rosé wine [23], consistent with the observation that rotundone is located in the grape berry skin [4]. To maximize rotundone extraction rate from grape to wine beyond the observed $10 \%$, it is essential to identify the key factors affecting rotundone extraction during fermentation.

This study investigated the influences of fortification winemaking techniques on the concentration of rotundone and other major wine volatiles in wine, and identified two main factors affecting rotundone extraction rate. This winemaking technique can be used to enhance rotundone extraction during fermentation and increase the quality of wine.

\section{Materials and Methods}

\subsection{Chemicals}

Rotundone ((3S,5R,8S)-3,4,5,6,7,8-hexahydro-3,8-dimethyl-5-(prop-1-en-2-yl)-1(2H)-azulenone) and isotope labelled d5-rotundone were synthesised by Australian Wine Research Institute as previously described [6,7]. Analytical standard grade 4-octanol, ethyl acetate, ethyl butanoate, ethyl hexanoate, hexyl acetate, ethyl octanoate, ethyl nonanoate, ethyl decanoate, diethyl butanedioate, 3-methylbutyl acetate, isobutanol, isopentanol and phenylethyl alcohol were purchased by Sigma-Aldrich (Castile Hill, NSW, Australia). All the working solutions of standards were prepared in ethanol and stored at $4{ }^{\circ} \mathrm{C}$. Liquid chromatography (LC)-grade ethyl acetate, n-pentane, methanol and ethanol were purchased from Rowe Scientific (Doveton, Vic, Australia). Analytical-grade tartaric acid, potassium L-tartrate monobasic and other chemicals were purchased from Sigma-Aldrich. Milli-Q system (Millipore Australia, Bayswater, Victoria, Australia) was used to purify water. 


\subsection{Vineyard and Winery Site}

Grapes for the current fermentation trial were collected from a commercial vineyard located in the Grampians wine region of Victoria, Australia (The Old Block, Mount Langi Ghiran, $37.31^{\circ} \mathrm{S}$, $\left.143.15^{\circ} \mathrm{E}\right)$. Weather data is recorded at the nearest Bureau of Meteorology (BOM) weather station at Ararat Prison (Australian BOM Station No. 089085), which is approximately $15.5 \mathrm{~km}$ east of the experimental vineyard. The long-term mean January temperature (MJT) and annual average rainfall recorded was $19.1^{\circ} \mathrm{C}$ and $584.2 \mathrm{~mm}$ by February 2015, respectively. No significant disease or pest pressures were observed during the 2014-15 growing seasons. A total of $40 \mathrm{~kg}$ Vitis vinifera $\mathrm{cv}$. Shiraz grapes in whole bunch were harvested on 14th April 2015 from the high rotundone zone of the block as suggested previously $[15,16,24]$, packed in styrofoam boxes on dry ice, transferred to the University of Melbourne, and stored at $-20^{\circ} \mathrm{C}$ before further experiments.

\subsection{Small-Scale Winemaking Trial}

The experiment was conducted following the small-scale fermentation protocol established by the Irymple Research Centre of the Department of Economics, Development, Jobs, Transport and Resources of the Victorian Government (DEDJTR), as described earlier [25,26]. Five treatments were conducted with three replicates per treatment; where $500 \mathrm{~g}$ of de-stemmed grape berries were used for each treatment replicate in a 700-mL fermentation container. Fermentation treatments were conducted as follows: (i) no specific treatment for the control group; (ii) $30 \mathrm{~mL}$ of food grade ethanol was added into the musts on the 1st day of fermentation (Tf-day1); (iii) $30 \mathrm{~mL}$ of food grade ethanol was added into the musts on the 5 th day of fermentation (Tf-day5); (iv) $39.5 \mathrm{~g}$ of food grade sucrose was added into the musts on the 1st day of fermentation (Ts-day1); (v) $39.5 \mathrm{~g}$ of food grade sucrose was added into the musts on the 5 th day of fermentation (Ts-day5). The grape must was pressed on the 7th day of fermentation, and skin pomace was collected, weighed and sealed in zip-lock bags and frozen at $-20{ }^{\circ} \mathrm{C}$ for further analysis. The resultant wines were racked, filtered and cold stabilized, and then subject to rotundone analysis, conventional wine parameters and volatile analysis. The rotundone extraction rate in the resultant wine $\left(R_{\text {wine }}\right)$ and rotundone residue in pomace $\left(R_{\text {pomace }}\right)$ are calculated using the equations below:

$$
\begin{gathered}
R_{\text {wine }}=\left(C_{\text {wine }} \times M_{\text {wine }}\right) /\left(C_{\text {grape }} \times M_{\text {grape }}\right) \times 100 \% \\
R_{\text {pomace }}=\left(C_{\text {pomace }} \times M_{\text {pomace }}\right) /\left(C_{\text {grape }} \times M_{\text {grape }}\right) \times 100 \% .
\end{gathered}
$$

The total content of rotundone in grapes, wine and pomace was quantified by multiplying the concentration of rotundone $\left(C_{\text {grape }}, C_{\text {wine, }}, C_{\text {pomace }}\right)$ and the mass of each type of material $\left(M_{\text {grape }}\right.$, $\left.M_{\text {wine, }}, M_{\text {pomace }}\right)$. The percentage of rotundone distributed in wine and pomace were then obtained by dividing the rotundone content in each type of material with total rotundone content in grapes used for fermentation. Wine alcoholic strength, $\mathrm{pH}$, titratable acidity (TA), total red pigments, total phenolics, colour density, colour hue and degree of red pigment colouration were analysed using an ebullometer, $\mathrm{pH}$ meter, alkaline titration and spectrophotometer, respectively, following standard protocols [27].

\section{Commercial-Scale Winemaking Trial}

Three volume containers of grapes from the experimental block were harvested and fermented separately using industrial methods into three different batches: (i) conventional fermentation type: grapes were handpicked in bunches, destemmed, crushed and fermented naturally first, and commercial cultured yeast was added on the 4th day of fermentation (Lalvin Rhone 2226, Lallemand Australia Pty Ltd., Edwardstown, SA, Australia) (the day of harvest, destemming and processing was counted as day 0) (Tc-h); (ii) whole berry fermentation type: grapes were handpicked in bunches, destemmed with many berries remain whole, not crushed and fermented naturally, berries were then 
crushed and submerged into the liquid of fermentation on the 3rd day (Tc-berry) with addition of commercial yeast (Lalvin M, Lallemand Australia Pty Ltd., Edwardstown, SA, Australia); (iii) whole bunch fermentation: grapes were handpicked and started fermentation with addition of commercial yeast (Lalvin M, Lallemand Australia Pty Ltd., Edwardstown, SA, Australia), grape bunches were then crushed on the 5th day of fermentation (Tc-bunch). Each batch of fermentation contained a minimum of 1 tonne of fruit. Two hundred millilitres of wine samples were collected on a daily basis from day 1 of fermentation until pressing (day 7), except for the Tc-bunch trial, where no juice could be sampled until day 5 . Wine samples were immediately frozen at $-20{ }^{\circ} \mathrm{C}$ in winery to stop fermentation. All samples were then packed in styrofoam boxes on dry ice, transferred to the University of Melbourne, and stored at $-20{ }^{\circ} \mathrm{C}$ until further analysis. The alcoholic strength of the wine was analysed using an alcohol meter (Alcolyzer Wine M, Anton Paar, Graz, Austria).

\subsection{Headspace Solid-Phase Microextraction and Gas Chromatography Mass Spectrometry (HS-SPME-GC-MS)} Analysis of Rotundone in Grapes and Wine

Grape and wine samples were prepared for rotundone analysis based on established protocols [6]. For grape samples, $100 \mathrm{~g}$ of de-stemmed grape samples were sub-sampled, extracted for rotundone using 50\% ethanol and spiked with internal standard ( $100 \mu \mathrm{L}$ d5-rotundone, $516 \mathrm{ng} / \mathrm{mL}$ in ethanol) as described previously [17]. For pomace samples, $30 \mathrm{~g}$ of pomace were sub-sampled and added to $30 \mathrm{~mL}$ Milli-Q water before being homogenised with a hand-held blender. Sub-samples were centrifuged to separate solids and liquids. The solids were mixed with $30 \mathrm{~mL}$ ethanol, $30 \mathrm{~mL}$ water, and spiked with internal standard (100 $\mu \mathrm{L}$ d5-rotundone, $516 \mathrm{ng} / \mathrm{mL}$ in ethanol), then shaken for $24 \mathrm{~h}$ at $22{ }^{\circ} \mathrm{C}$ and sonicated before reintroducing the liquids. Sub-samples were then centrifuged and filtered (1.6 $\mu \mathrm{m}$ glass fibre) to obtain a berry extract filtrate, which was topped up to $200 \mathrm{~mL}$ with deionised water. For wine samples, $100 \mathrm{~mL}$ of samples were sub-sampled, spiked with internal standard ( $100 \mu \mathrm{L}$ d5-rotundone, $516 \mathrm{ng} / \mathrm{mL}$ in ethanol). Spiked grape extract, pomace extract and wine extract samples were then subjected to solid phase extraction (SPE) as reported previously [6]. The SPE residue supernatant was air dried with nitrogen and reconstituted in $0.5 \mathrm{~mL}$ ethanol and $9 \mathrm{~mL}$ Milli-Q water. The samples were then analysed and quantified with SPME-GC-MS following the established method [6]. The target ions used were $m / z 223$ with 208 as qualifier ions for d5-rotundone, while $m / z 218$ with $m / z 203$ were used for rotundone.

\subsection{Headspace Solid-Phase Microextraction and Gas Chromatography Mass Spectrometry (HS-SPME-GC-MS) Analysis of Wine Volatiles}

Wine samples were prepared for major wine volatile analysis based on the protocol proposed by Siebert et al. [28] with some modifications. Here, 1-mL wine samples were diluted with $9 \mathrm{~mL}$ of Milli-Q water into HS-SPME vial (Agilent Technologies, $20 \mathrm{~mL}$ ) with addition of $2 \mathrm{~g}$ of sodium chloride and $200 \mu \mathrm{L}$ of 4-octanol (internal standard) $(10 \mathrm{mg} / \mathrm{L})$ and ethyl nonanoate (quality control) $(10 \mathrm{~mL} / \mathrm{L})$. The vial and its contents were shaken at $220 \mathrm{rpm}$ and heated to $35^{\circ} \mathrm{C}$. A polydimethylsiloxane (PDMS, Agilent Technologies, Santa Clara, CA, USA) $100 \mu \mathrm{m}$ fibre was exposed to the headspace and agitated for $10 \mathrm{~min}$. An Agilent Technologies 6850 series II (GC; Agilent Technologies, Santa Clara, CA, USA) equipped with an Agilent PAL 120 multipurpose auto-sampler and coupled with an Agilent 5873 mass selective detector (MSD) was used for volatile assessments. The instruments were controlled using Agilent G1701EA MSC ChemStation software in conjunction with Agilent PAL Sampler Software Control B.01.04 for ChemStation. The GC was fitted with a J \& W DB-wax column (30 m $\times 0.25 \mathrm{~mm}, 0.25 \mu \mathrm{m}$ film df) with helium as carrier gas (ultrahigh purity, BOC Australia, North Ryde, NSW, Australia). The equipment parameters used for wine volatile analysis have been described previously [26]. Alkane standards (C7-C30) were analysed to calculate retention indices. Wine volatiles were identified/quantified by comparing the mass spectra and retention indices with the NIST library (Mass Spectrometry Data Centre, National Institute of Standards and Technology, Gaithersburg, MD, USA) in ChemStation and NIST Chemistry Webbook database (National Institute of 
Standards and Technology, Gaithersburg, MD, USA) and standard solutions obtained. All compounds were quantified based on GC peak ratio of individual compounds and internal standard, and the calibration curves generated from the standard solutions. Quality control, blank SPME runs and blank internals standards were checked regularly.

\section{Statistical Analysis}

Biochemical test results, rotundone concentration and wine volatiles of different treatment groups were subjected to one-way analysis of variance (ANOVA) at the $p<0.05$ significance level using Student-Newman-Keuls as a post hoc test (CoStat, version 6.4, CoHort software, Monterey, CA, USA). The trends of rotundone accumulation during winemaking were calculated using the curve fitting tool in in MatLab®ver. 2014a (The MathWorks, Inc., Matick, MA, USA).

\section{Results and Discussion}

The effect of ethanol and sugar addition on the extraction of rotundone into wine was investigated by small-scale fermentation. Wine alcoholic strength and colour profiles were compared amongst treatment groups (Table 1). As expected, significantly higher alcohol concentration was observed in four treatments compared to control. All fortification treatments had higher total phenolics and total red pigments compared to the control group. Ethanol and sucrose treatments on the 1st day (Tf-day1 and Ts-day 1) had a slight but significant reduction in wine colour hue compared to the control group, while treatments on the 5 th day had no significant reduction. No significant differences were observed in wine colour density and degree of red pigment colouration amongst all experimental groups. Few researchers have compared anthocyanins and phenolics content between non-fortified and fortified wine, but many have investigated the influences of alcohol removal on the chemical composition of wine with inconsistent results [29-31]. Motta, Guaita, Petrozziello, Ciambotti, Panero, Solomita and Bosso [30], observed higher concentration of total anthocyanins, flavonoid and colour intensity in treatments with $5 \%$ of alcohol removal. While another studies reported no significant differences between dealcoholized and control wine in total anthocyanins content and colourant intensity in Merlot, Aglianico, Piedirosso and Cabernet Sauvignon [31,32]. In the current study, higher concentration of anthocyanins and phenolics observed in fortified wine is likely due to the elevated concentration of ethanol, which is a good solvent for polyphenol extraction from the grape skins [33].

Table 1. Comparison of wine chemical parameters for small-scale fermentation trials ${ }^{1}$.

\begin{tabular}{cccccc}
\hline Wine Parameters & Control & Tf-day $\mathbf{1}$ & Tf-day $\mathbf{5}$ & Ts-day $\mathbf{1}$ & Ts-day $\mathbf{5}$ \\
\hline Alcohol $(\% \mathrm{v} / \mathrm{v})$ & $12.7 \pm 0.4 \mathrm{c}$ & $16.8 \pm 0.5 \mathrm{a}$ & $16.9 \pm 0.1 \mathrm{a}$ & $15.2 \pm 0.6 \mathrm{~b}$ & $15.3 \pm 0.2 \mathrm{~b}$ \\
Total phenolics (a.u.) & $36.2 \pm 1.8 \mathrm{~b}$ & $44.3 \pm 1.1 \mathrm{a}$ & $43.0 \pm 1.2 \mathrm{a}$ & $44.0 \pm 0.5 \mathrm{a}$ & $43.9 \pm 0.7 \mathrm{a}$ \\
Total red pigments (a.u.) & $14.3 \pm 0.1 \mathrm{c}$ & $20.1 \pm 0.8 \mathrm{a}$ & $18.9 \pm 0.4 \mathrm{~b}$ & $19.0 \pm 0.1 \mathrm{~b}$ & $18.1 \pm 1.1 \mathrm{~b}$ \\
Wine colour density & $9.1 \pm 0.8$ & $10.6 \pm 1.3$ & $9.1 \pm 1.4$ & $11.0 \pm 0.5$ & $9.4 \pm 0.5$ \\
$\quad$ Wine colour hue & $0.63 \pm 0.02 \mathrm{a}$ & $0.54 \pm 0.04 \mathrm{~b}$ & $0.60 \pm 0.03 \mathrm{ab}$ & $0.53 \pm 0.02 \mathrm{~b}$ & $0.60 \pm 0.00 \mathrm{ab}$ \\
$\begin{array}{c}\text { Degree of red pigment } \\
\text { colouration (\%) }\end{array}$ & $13.9 \pm 0.9$ & $14.3 \pm 2.3$ & $12.1 \pm 1.8$ & $15.0 \pm 0.8$ & $12.2 \pm 0.5$ \\
\hline 1 One-way ANOVA was conducted at $p<0.05 ; \mathrm{a}, \mathrm{b}, \mathrm{c}$ are used to indicate statistically significant differences.
\end{tabular}

${ }^{1}$ One-way ANOVA was conducted at $p<0.05 ; \mathrm{a}, \mathrm{b}, \mathrm{c}$ are used to indicate statistically significant differences.

To understand the influences of different fortification methods on rotundone extraction from grape to wine, the concentration of rotundone in wine and fermented pomace were analysed separately for each treatment (Figure 1A). Significantly higher concentrations of rotundone were observed in Tf-day1 (52.81 ng/L), Tf-day5 (52.76 ng/L) and Ts-day1 (47.87 ng/L) treatments, compared to the control (35.92 ng/L) and Ts-day5 (32.70 ng/L). Similarly, statistically significant differences were also observed amongst the fermented pomace of treatments. Higher concentrations of rotundone in ethanol and sugar fortified treatments were due to the higher alcohol content. Siebert, Wood, Elsey and Pollnitz [6] first investigated rotundone recovery rate from grape berries using different extraction methods, and 
observed higher rotundone recovery $(45-100 \%)$ when using ethanol as extraction solvent compared to extractions without ethanol (16-28\%). Based on this, rotundone extraction method used for rotundone quantification was established using 50\% ethanol as solvent to extract rotundone from grapes, which is now accepted as the standard rotundone extraction/quantification method $[6,10,16,19]$. In Ts-day 5 treatment, it would take time for added sugar to be fermented into alcohol after the addition in the 5th day. No obvious rotundone increase was observed in the Ts-day5 treatment, likely due to the less rotundone extraction time after wine alcohol reaches a relatively high level. Rotundone, similar to other sesquiterpenes, exists in the exocap of the grape berry (skin), rather than the mesocarp (flesh) $[5,14,20]$. Therefore, longer contact time between grape exocap and the fermented juice is critical for rotundone extraction.
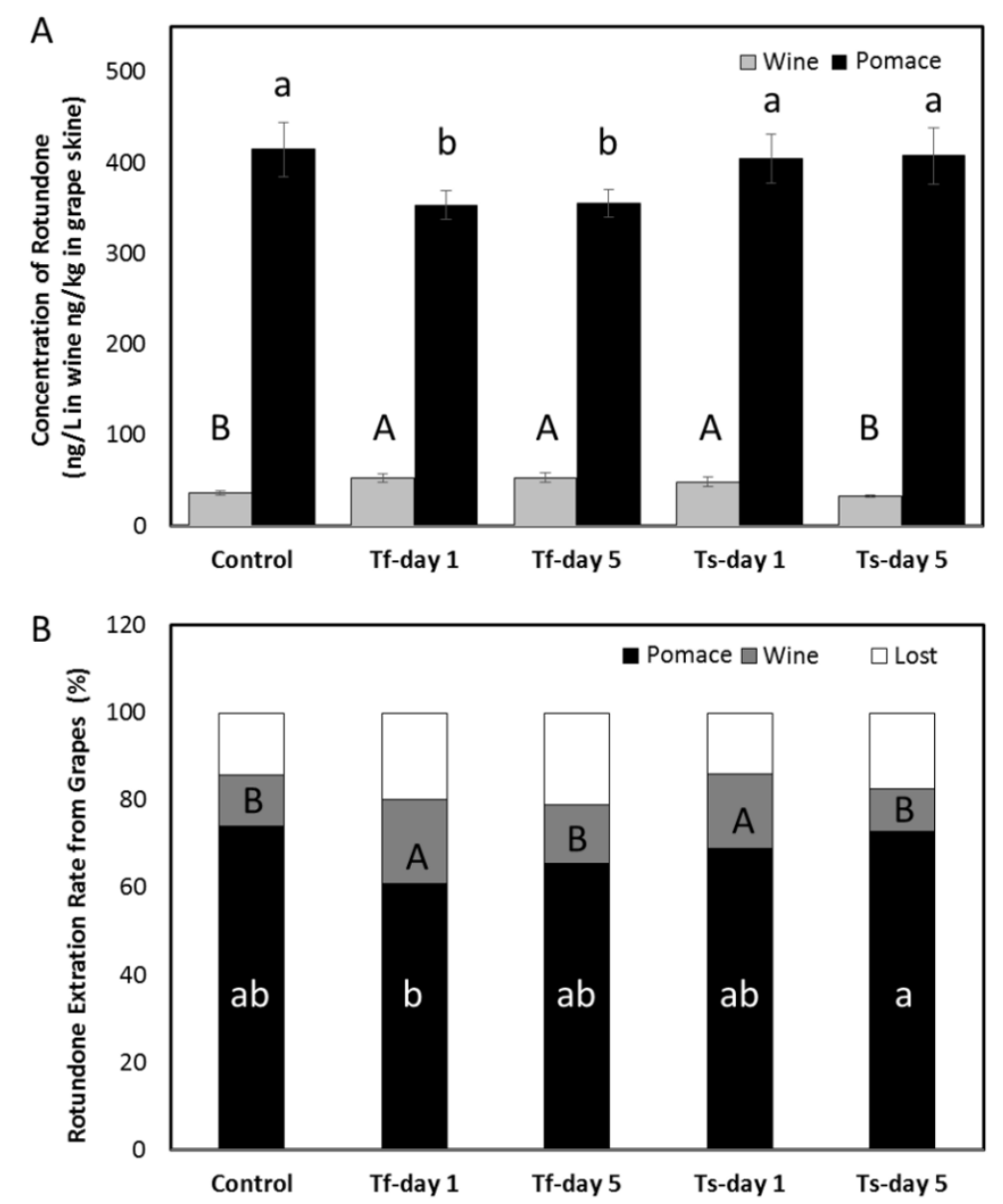

Figure 1. Influences of fortified winemaking techniques on rotundone content in wine. (A): The concentration of rotundone in the resultant wine and residual grape pomace was compared with one-way ANOVA analysis $(p<0.05)$, significant differences were expressed using $\mathbf{a}, \mathbf{b}$. (B) The extraction rate of rotundone in the resultant wine and residual rotundone in grape pomace was compared with one-way ANOVA analysis $(p<0.05)$, significant differences were expressed using A, B and $a, b$, respectively.

To calculate the rotundone extraction rate in the resultant wine, the concentration of rotundone in grape berries used for fermentation trials were quantified to be $297.61 \mathrm{ng} / \mathrm{kg}$. Significantly higher percentages of rotundone extraction rate in wine were observed in the Tf-day $1(19.20 \%)$ and Ts-day1 $(17.06 \%)$ treatments compared to the control (11.72\%), Tf-day5 (13.43\%) and Ts-day5 $(9.64 \%)$ groups (Figure 1B). Consequently, lower rotundone residual rate was observed in Tf-day1 (60.93\%) compared to Ts-day5 $(72.92 \%)$, but not statistically different to the control $(74.08 \%)$, Tf-day5 (65.04\%) and Ts-day1 $(68.96 \%)$. This could be due to the variations in winemaking sediment (lees) lost during the winemaking 
process. Higher rotundone extraction rate for the Tf-day1 and Ts-day1 treatments further confirmed the hypothesis that ethanol played important role in rotundone extraction from grape berries into wine, and lower extraction rates in Tf-day 5 and Ts-day 5 treatments validated the importance of extraction time to the rate of rotundone recovery. Only around $10 \%$ of the total rotundone is expected at the end of fermentation [21], while our results show that the rotundone recovery rate can be increased up to $19.20 \%$ (Tf-day1) from $11.72 \%$ (control). Human detection threshold for rotundone can be as low as $16 \mathrm{ng} / \mathrm{L}$ in red wine [7]. Shiraz wine with around $20 \mathrm{ng} / \mathrm{L}$ rotundone could be identified as moderate pepper aroma intensity by trained sensory panel, while $75 \mathrm{ng} / \mathrm{L}$ would be considered as high intensity [7]. Therefore, significant increases in rotundone recover rate and concentration as shown in the current study would have a significant sensory impact on wine aroma and flavour. These results also represent a great practical value for wine industry, which could consider the possibility of producing a 'spicier' wine using fortification.

Major wine volatiles in the fermentation trials were quantified and compared (Table 2). Variations in volatile compounds amongst treatment groups were mainly observed in esters, rather than alcohols. Significantly higher concentrations of ethyl acetate (fruity, pineapple odour) were observed in the Tf-day1 treatment, compared to the control and other treatments. Both treatments on the 1st day of fermentation (Tf-day1 and Ts-day1) had significantly higher concentration of 3-methylbutyl acetate (banana odour) and ethyl butanoate (kiwi, ripe strawberry odour) compared to the control and other treatments. Hexyl acetate was only detected in Tf-day 1 treatment, but not in other experimental groups. Significantly lower concentrations of ethyl hexanoate (green apple odour) were observed in all treatments except Ts-day1, compared to the control. Ethanol treatment groups (Tf-day1 and Tf-day5) had significantly lower concentration of ethyl octanoate (apple skin odour) compared to the control. All treatments, except Ts-day5, tended to have a lower concentration of methyl nonanoate (coconut odour) compared to the control. Sugar treatment groups (Ts-day1 and Ts-day5) had significantly higher concentrations of isopentanol (earthy odour) compared to the control. Significant differences was also observed in phenylethyl alcohol (floral, rose odour), where large increases were detected in treatments on the 5th day of fermentation (Tf-day5 and Ts-day5). Interestingly, 2,3-butanediol was only detected in fortification treatments, rather than the control. Nevertheless, this compound does not have a characteristic odour, and has no impacts on the aroma of the resultant wine. The volatile components of Australian fortified wine have been investigated since the 1970s, and most volatiles identified here have been reported previously [34]. Fortified wine and still wine are made using different types of Vitis cultivars, with over 100 varieties of grapes could be used in port wine production, including five main cultivars, Tinta Barroca, Tinta Cao, Tinta Roriz (Tempranillo), Touriga Francesa and Touriga Nacional [35], but there is almost no research to compare wine volatile compositions between fortified and non-fortified wine made from the same variety. Studies related to alcohol manipulation focused on the impacts of dealcoholisation on wine volatile profile, which could reflect the importance of alcohol to wine aroma profile. A recent study compared the influences of two different dealcoholisation techniques on wine volatile profile, and observed significantly lower concentration of most esters and alcohols in dealcoholized wine [30]. The losses of volatiles may be due to dealcoholisation techniques and loss of alcohol, as most volatiles are ethanol-soluble. Consequently, dealcoholisation has dramatic influences on the sensory attributes of the resultant wine, importantly fruity and floral notes, aroma intensity, complexity and body. The fortification process of winemaking may potentially affect wine volatile and sensory profile. Much more research is required in this field to explore the possibility of applying fortification methods to grape varieties rather than those used traditionally. 
Table 2. Major wine volatiles detected for the wines made in small-scale fermentations $(p<0.05)$.

\begin{tabular}{|c|c|c|c|c|c|c|c|c|c|}
\hline \multirow{2}{*}{ Peak Number } & \multirow{2}{*}{ LRI-Lit $^{1}$} & \multirow{2}{*}{ LRI-Act $^{2}$} & \multirow{2}{*}{ Compound Name } & \multirow{2}{*}{ Odour $^{3}$} & \multicolumn{5}{|c|}{ Concentration of Major Volatile in Studied Wine Samples ${ }^{4}$} \\
\hline & & & & & Control & Tf-day 1 & Tf-day 5 & Ts-day 1 & Ts-day 5 \\
\hline \multicolumn{10}{|c|}{ Acetate } \\
\hline $1^{5}$ & 880 & 841 & Ethyl acetate (mg/L) & Fruity, pineapple & $3.8 \pm 0.3 \mathrm{~b}^{6}$ & $5.7 \pm 0.2 \mathrm{a}$ & $4.6 \pm 0.1 \mathrm{~b}$ & $4 \pm 0.7 \mathrm{~b}$ & $4 \pm 0.6 \mathrm{~b}$ \\
\hline 4 & 1115 & 1125 & 3-Methylbutyl acetate (mg/L) & Fruity, banana & $1.4 \pm 0.3 \mathrm{c}$ & $5.6 \pm 1 \mathrm{a}$ & $0.9 \pm 0.2 \mathrm{c}$ & $3.5 \pm 0.7 \mathrm{~b}$ & $1.5 \pm 0.8 \mathrm{c}$ \\
\hline 8 & 1275 & 1272 & Hexyl acetate $(\mu \mathrm{g} / \mathrm{L})$ & Red fruit, herb & $\operatorname{tr}^{7}$ & $53 \pm 4$ & $\operatorname{tr}$ & $\operatorname{tr}$ & $\operatorname{tr}$ \\
\hline \multicolumn{10}{|c|}{ Straight chain esters } \\
\hline 2 & 1035 & 1042 & Ethyl butanoate (mg/L) & $\begin{array}{c}\text { Ripe kiwi, ripe } \\
\text { strawberry, cheese }\end{array}$ & $1.5 \pm 0.2 \mathrm{ab}$ & $1.9 \pm 0.2 \mathrm{a}$ & $1.3 \pm 0.1 \mathrm{~b}$ & $2.0 \pm 0.2 \mathrm{a}$ & $1.4 \pm 0.3 \mathrm{~b}$ \\
\hline 7 & 1240 & 1235 & Ethyl hexanoate $(\mathrm{mg} / \mathrm{L})$ & Fruity, green apple & $2.1 \pm 0.2 \mathrm{a}$ & $1.2 \pm 0.2 \mathrm{~b}$ & $0.4 \pm 0.0 \mathrm{~b}$ & $2.3 \pm 0.2 \mathrm{a}$ & $1 \pm 0.8 \mathrm{~b}$ \\
\hline 11 & 1440 & 1435 & Ethyl octanoate $(\mu \mathrm{g} / \mathrm{L})$ & Waxy, apple skin, fruity & $688 \pm 70 \mathrm{a}$ & $407 \pm 35 b$ & $137 \pm 12 b$ & $795 \pm 49 \mathrm{a}$ & $352 \pm 271 b$ \\
\hline 14 & 1643 & 1638 & Ethyl decanoate $(\mu \mathrm{g} / \mathrm{L})$ & Waxy, fruity & $83 \pm 17$ & $72 \pm 27$ & $56 \pm 4$ & $113 \pm 6$ & $77 \pm 46$ \\
\hline \multicolumn{10}{|c|}{ Other esters } \\
\hline 12 & 1491 & 1491 & Methyl nonanoate $(\mu \mathrm{g} / \mathrm{L})$ & Coconut & $109 \pm 19 \mathrm{ab}$ & $53 \pm 11 b$ & $74 \pm 24 b$ & $59 \pm 36 \mathrm{~b}$ & $135 \pm 25 \mathrm{a}$ \\
\hline \multicolumn{10}{|c|}{ Alcohol } \\
\hline 3 & 1090 & 1100 & Isobutanol $(\mu \mathrm{g} / \mathrm{L})$ & Fruity & $405 \pm 48$ & $368 \pm 45$ & $480 \pm 27$ & $448 \pm 27$ & $462 \pm 62$ \\
\hline 5 & 1134 & 1151 & 1-Butanol $(\mu \mathrm{g} / \mathrm{L})$ & Fusel, spirituous, medicine & $6.0 \pm 0.8$ & $7.9 \pm 2.5$ & $5.9 \pm 2.4$ & $5.0 \pm 2$ & $4.2 \pm 0.4$ \\
\hline 6 & 1185 & 1214 & Isopentanol (mg/L) & Earthy, burnt & $682 \pm 12 b$ & $701 \pm 36 \mathrm{ab}$ & $708 \pm 9 \mathrm{ab}$ & $779 \pm 14 \mathrm{a}$ & $780 \pm 57 a$ \\
\hline 9 & 1360 & 1360 & 1-Hexanol (mg/L) & Green, floral, spice & $2.4 \pm 0.3$ & $1.4 \pm 1.3$ & $0.8 \pm 1.2$ & $1.7 \pm 0.2$ & $1.8 \pm 0.4$ \\
\hline 15 & 1912 & 1917 & Phenylethyl Alcohol (mg/L) & Floral, rose & $6.9 \pm 0.5 c$ & $6.1 \pm 0.3 \mathrm{~d}$ & $8.4 \pm 0.5 b$ & $8.8 \pm 0.1 \mathrm{~b}$ & $10.1 \pm 0.1 \mathrm{a}$ \\
\hline \multicolumn{10}{|c|}{ Miscellaneous compounds } \\
\hline 13 & 1543 & 1550 & 2, 3-Butanediol $(\mu \mathrm{g} / \mathrm{L})$ & Odorless & $\operatorname{tr}$ & $44 \pm 9$ & $44 \pm 34$ & $59 \pm 0$ & $50 \pm 4$ \\
\hline
\end{tabular}

${ }^{1}$ Linear retention index obtained from NIST chemistry webbook; ${ }^{2}$ Actual linear retention index calculated based on alkane standards; ${ }^{3}$ Odour of compounds obtained from Flavornet, The Good Scents Company and The Pherobase; ${ }^{4}$ Concentration of ethyl acetate, diethyl butanedioate, methyl nonanoate, isobutanol, 1-butanol, 4-octanone, 2,3-butanediol were semi-quantified as 4-octanol correspondent; ${ }^{5}$ Internal standard 4-octanol and quality control standard ethyl nonanate were not shown in the table; ${ }^{6}$ One -way ANOVA conduced to compare experimental groups at $p<0.05, \mathrm{a}, \mathrm{b}, \mathrm{c}$ were used to indicate statistically significant differences; ${ }^{7}$ tr, trace, below detection threshold. 
Rotundone extraction during primary wine fermentation at different alcoholic strengths was further investigated under commercial winemaking conditions (Figure 2). Previous studies reported that rotundone extraction was concentrated during the 2nd to 5th day of fermentation $[5,20]$; however, rotundone was continuously extracted until pressing (7th day of fermentation). Increasing rotundone concentration by alcoholic strength of wine was observed for the Tc-h $\left(y=4.42 \mathrm{e}^{0.1212 x}, R^{2}=0.9627\right.$, RSME $=1.486)$, Tc-berry $\left(y=5.966 \mathrm{e}^{0.0773 x}, R^{2}=0.882, \mathrm{RSME}=1.837\right)$ and Tc-bunch treatments $\left(y=9.007 \mathrm{e}^{0.07415 x}, R^{2}=0.9351, \mathrm{RSME}=1.183\right)$. Increasing extraction of the mesocarp-associated compounds is expected as fermentation progresses due to the increasing solubility of the aroma compounds in ethanol [36]. Different concentrations of rotundone were observed between the commercial trials, due to the differences in winemaking technique and potentially to the different sources of grape berries. The grape berries for each winemaking trial were harvested from different sectors of experimental vineyard with large within-vineyard variations in rotundone [15,16,24]. Even though a different type of commercial yeast was used for Tc-h, there is no evidence showing that yeast may alter rotundone extraction. The impacts of yeast on wine rotundone are not within the scope of the current study. Nevertheless, three types of commercial fermentations showed similar trends of rotundone accumulation in according to wine alcoholic strength, which further demonstrated the critical role of ethanol in rotundone extraction. In future researches, more commercial scale trials should be done to evaluate the influences of fortification techniques on the chemical compositions and sensory attributes of wine. A different style of wine, such as 'spicier' fortified wine, may be created using this technique.

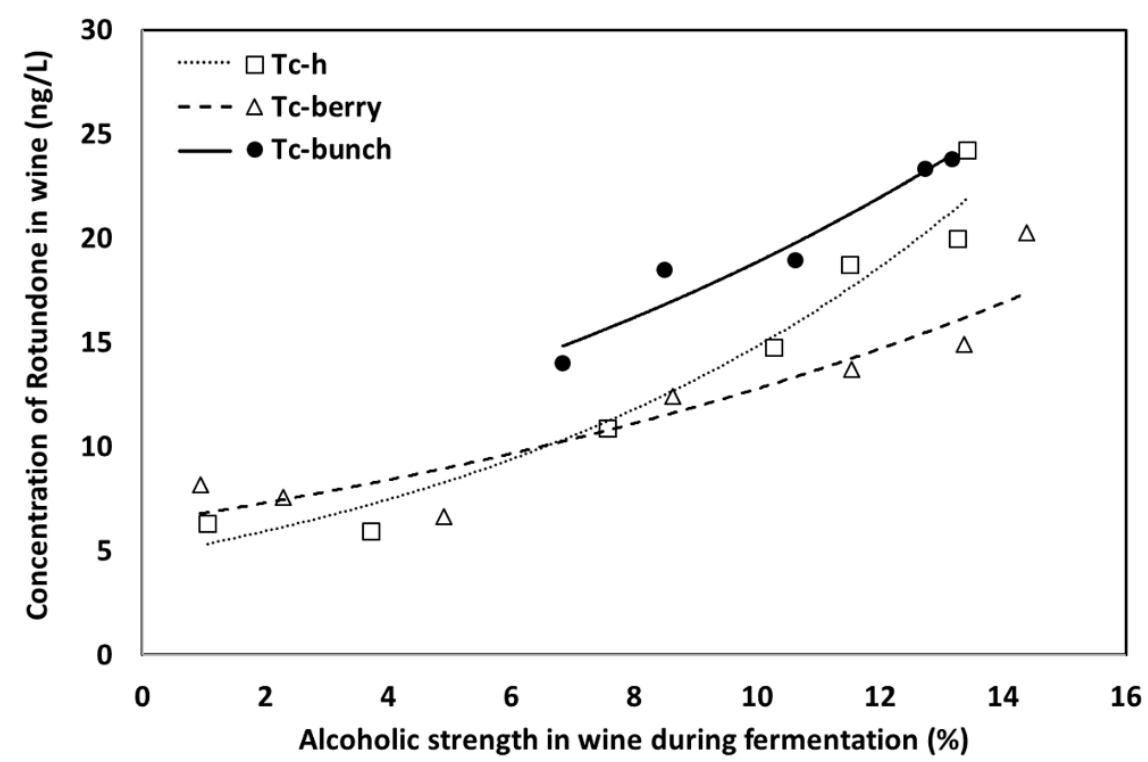

Figure 2. Concentration of rotundone at different alcoholic strength level during winemaking. Wine samples from three commercial fermentation trials were analysed for rotundone concentration on a daily basis from first day of crush until pressing. Tc-h represents crushed berry fermentation $\left(y=4.42 \mathrm{e}^{0.1212 x}, R^{2}=0.9627, \mathrm{RSME}=1.486\right)$; Tc-berry represents whole berry fermentation $\left(y=5.966 \mathrm{e}^{0.0773 x}, R^{2}=0.882, \mathrm{RSME}=1.837\right)$; Tc-bunch represents whole bunch fermentation $\left(y=9.007 \mathrm{e}^{0.07415 x}, R^{2}=0.9351, \operatorname{RSME}=1.183\right)$.

\section{Conclusions}

This study is novel in many aspects. It is the first study to identify a winemaking technique able to increase the extraction rate of rotundone from grapes to wine, and the first study to investigate the influences of fortification techniques on the volatiles profile of wine using non-traditional port wine cultivar. Fortification treatments have been demonstrated to significantly improve the total phenolics and red pigments components in the resultant wine. Importantly, fortification could significantly 
enhance rotundone extraction rate, with up to $19.20 \%$ recovered in the resultant wine, which is the highest rate reported so far. Two main factors important for rotundone extraction were identified: alcohol and pomace-wine contact time at high alcohol level, which could provide guidance for the wine industry to manipulate wine rotundone in commercial productions. Fortification could modify wine volatiles profile, mainly in esters, which consequently would affect the aromatic attributes of the resultant wine. Further studies need to be done to further investigate the influences of fortification on wine chemical and sensory attributes in detail.

Acknowledgments: This work was sponsored by the Rathbone Wine Group and The University of Melbourne. The work was performed at the University of Melbourne and Mount Langi Ghiran Winery. Funding was received from the Faculty of Veterinary and Agricultural Sciences, University of Melbourne. The authors thank Damien Sheehan, Ben Haines and Jess Robertson (Rathbone Wine Group) for their support and assistance with the fermentation trials. The authors would also like to thank Markus Herderich, Mark Krstic and Tracey Siebert (Australian Wine Research Institute) for their support and providing chemical standards used for this study.

Author Contributions: Pangzhen Zhang conceived and designed the experiments; Pangzhen Zhang and Fangping Luo performed the experiments; Pangzhen Zhang, Fangping Luo and Kate Howell analyzed the data; Pangzhen Zhang, Fangping Luo and Kate Howell contributed reagents/materials/analysis tools; Pangzhen Zhang, Fangping Luo and Kate Howell wrote the paper.

Conflicts of Interest: The authors declare no conflict of interest. The founding sponsors had no role in the design of the study; in the collection, analyses, or interpretation of data; in the writing of the manuscript, and in the decision to publish the results.

\section{References}

1. Dunlevy, J.D.; Kalua, C.M.; Keyzers, R.A.; Boss, P.K. The production of flavour \& aroma compounds in grape berries. In Grapevine Molecular Physiology E Biotechnology, 2nd ed.; Roubelakis-Angelakis, K., Ed.; Springer: Dordrecht, the Netherlands, 2009; pp. 293-340.

2. Maicas, S.; Mateo, J.J. Hydrolysis of terpenyl glycosides in grape juice and other fruit juices: A review. Appl. Microbiol. Biotechnol. 2005, 67, 322-335. [CrossRef] [PubMed]

3. Jeffery, D.; Siebert, T.; Capone, D.; Pardon, K.; Van Leeuwen, K.; Solomon, M. Grape and wine pepper aroma-analytically challenging but we sniff it out in the end. In Technical review; The Australian Wine Research Institute: Urrbrae, SA, Australia, 2009; pp. 11-16.

4. Herderich, M.J.; Siebert, T.E.; Parker, M.; Capone, D.L.; Mayr, C.; Zhang, P.; Geffroy, O.; Williamson, P.; Francis, I.L. Synthesis of the ongoing works on rotundone, an aromatic compound responsible for the peppery notes in wines. Internet J. Enol. Vitic. 2013, 6, 1-6.

5. Herderich, M.J.; Siebert, T.E.; Parker, M.; Capone, D.L.; Jeffery, D.W.; Osidacz, P.; Francis, I.L. Spice up your life: Analysis of key aroma compounds in Shiraz. In Flavor Chemistry of Wine and Other Alcoholic Beverages; American Chemical Society: Washington, DC, USA, 2012; pp. 3-13.

6. Siebert, T.E.; Wood, C.; Elsey, G.M.; Pollnitz, A.P. Determination of rotundone, the pepper aroma impact compound, in grapes and wine. J. Agric. Food Chem. 2008, 56, 3745-3748. [CrossRef] [PubMed]

7. Wood, C.; Siebert, T.E.; Parker, M.; Capone, D.L.; Elsey, G.M.; Pollnitz, A.P.; Eggers, M.; Meier, M.; Vössing, T.; Widder, S.; et al. From wine to pepper: Rotundone, an obscure sesquiterpene, is a potent spicy aroma compound. J. Agric. Food Chem. 2008, 56, 3738-3744. [CrossRef] [PubMed]

8. Zhang, P.; Howell, K.; Krstic, M.; Herderich, M.; Barlow, E.W.R.; Fuentes, S. Environmental factors and seasonality affect the concentration of rotundone in vitis vinifera 1 . Cv. Shiraz wine. PLoS ONE 2015, 10, e0133137. [CrossRef] [PubMed]

9. Davies, C.; Nicholson, E.L.; Böttcher, C.; Burbidge, C.A.; Bastian, S.E.; Harvey, K.E.; Huang, A.-C.; Taylor, D.K.; Boss, P.K. Shiraz wines made from grape berries (vitis vinifera) delayed in ripening by plant growth regulator treatment have elevated rotundone concentrations and "pepper" flavor and aroma. J. Agric. Food Chem. 2015, 63, 2137-2144. [CrossRef] [PubMed]

10. Geffroy, O.; Dufourcq, T.; Carcenac, D.; Siebert, T.; Herderich, M.; Serrano, E. Effect of ripeness and viticultural techniques on the rotundone concentration in red wine made from vitis vinifera L. cv. Duras. Aust. J. Grape Wine Res. 2014, 20, 401-408. [CrossRef] 
11. Geffroy, O.; Siebert, T.; Herderich, M.; Mille, B.; Serrano, E. On-vine grape drying combined with irrigation allows to produce red wines with enhanced phenolic and rotundone concentrations. Sci. Hortic. 2016, 207, 208-217. [CrossRef]

12. Geffroy, O.; Yobrégat, O.; Dufourcq, T.; Siebert, T.; Serrano, E. Certified clone and powdery mildew impact rotundone in red wine from vitis vinifera L. cv. Duras N. OENO One 2015, 49, 231-240. [CrossRef]

13. Herderich, M.; Barter, S.; Black, C.A.; Bramley, R.; Capone, D.; Dry, P.; Siebert, T.; Zhang, P. Terroir effects on grape and wine aroma compounds. In Advances in wine research; American Chemical Society: Washington, DC, USA, 2015; pp. 131-146.

14. May, B.; Lange, B.M.; Wüst, M. Biosynthesis of sesquiterpenes in grape berry exocarp of vitis vinifera 1.: Evidence for a transport of farnesyl diphosphate precursors from plastids to the cytosol. Phytochemistry 2013, 95, 135-144. [CrossRef] [PubMed]

15. Scarlett, N.J.; Bramley, R.G.V.; Siebert, T.E. Within-vineyard variation in the 'pepper' compound rotundone is spatially structured and related to variation in the land underlying the vineyard. Aust. J. Grape Wine Res. 2014, 20, 214-222. [CrossRef]

16. Zhang, P.; Barlow, S.; Krstic, M.; Herderich, M.; Fuentes, S.; Howell, K. Within-vineyard, within-vine, and within-bunch variability of the rotundone concentration in berries of vitis vinifera L. Cv. Shiraz. J. Agric. Food Chem. 2015, 63, 4276-4283. [CrossRef] [PubMed]

17. Zhang, P.; Fuentes, S.; Siebert, T.; Krstic, M.; Herderich, M.; Barlow, E.W.R.; Howell, K. Terpene evolution during the development of vitis vinifera L. cv. Shiraz grapes. Food Chem. 2016, 204, 463-474. [CrossRef] [PubMed]

18. Zhang, P.; Fuentes, S.; Siebert, T.; Krstic, M.; Herderich, M.; Barlow, E.W.R.; Howell, K. Comparison data of common and abundant terpenes at different grape development stages in shiraz wine grapes. Data Brief 2016, 8, 1127-1136. [CrossRef] [PubMed]

19. Zhang, P.; Fuentes, S.; Wang, Y.; Deng, R.; Krstic, M.; Herderich, M.; Barlow, E.W.R.; Howell, K. Distribution of rotundone and possible translocation of related compounds amongst grapevine tissues in vitis vinifera 1. Cv. Shiraz. In Front. Plant Sci.; 2016. Available online: https://www.ncbi.nlm.nih.gov/pmc/articles/ PMC4914589/ (accessed on 27 May 2017).

20. Siebert, T.E.; Solomon, M.R. Rotundone: Development in the grape and extraction during fermentation. In Proceedings of the fourteenth Australian wine industry technical conference, Adelaide, Australia, July 2010; pp. 307-308.

21. Caputi, L.; Carlin, S.; Ghiglieno, I.; Stefanini, M.; Valenti, L.; Vrhovsek, U.; Mattivi, F. Relationship of changes in rotundone content during grape ripening and winemaking to manipulation of the 'peppery'character of wine. J. Agric. Food Chem. 2011, 59, 5565-5571. [CrossRef] [PubMed]

22. Capone, D.L.; Jeffery, D.W.; Sefton, M.A. Vineyard and fermentation studies to elucidate the origin of 1,8-cineole in australian red wine. J. Agric. Food Chem. 2012, 60, 2281-2287. [CrossRef] [PubMed]

23. Geffroy, O.; Siebert, T.; Silvano, A.; Herderich, M. Impact of winemaking techniques on classical enological parameters and rotundone in red wine at the laboratory scale. Am. J. Enol. Vitic. 2017, 68, 141-146. [CrossRef]

24. Bramley, R.; Siebert, T.; Herderich, M.; Krstic, M. Patterns of within-vineyard spatial variation in the 'pepper'compound rotundone are temporally stable from year to year. Aust. J. Grape Wine Res. 2017, 23, 42-47. [CrossRef]

25. Kilmister, R.L.; Mazza, M.; Baker, N.K.; Faulkner, P.; Downey, M.O. A role for anthocyanin in determining wine tannin concentration in shiraz. Food Chem. 2014, 152, 475-482. [CrossRef] [PubMed]

26. Zhang, P.; Wu, X.; Needs, S.; Fuentes, S.; Liu, D.; Howell, K. Influences of apical and basal defoliation on canopy structure and the biochemical composition of vitis vinifera cv. Shiraz grape and wine. Front. Chem. 2017, 5. [CrossRef]

27. Iland, P. Chemical Analysis of Grapes and Wine: Techniques and Concepts; Patrick Iland Wine Promotions: Campbelltown, Australia, 2004.

28. Siebert, T.E.; Smyth, H.E.; Capone, D.L.; Neuwohner, C.; Pardon, K.H.; Skouroumounis, G.K.; Herderich, M.J.; Sefton, M.A.; Pollnitz, A.P. Stable isotope dilution analysis of wine fermentation products by HS-SPME-GC-MS. Anal. Bioanal. Chem. 2005, 381, 937-947. [CrossRef] [PubMed]

29. Lisanti, M.T.; Gambuti, A.; Genovese, A.; Piombino, P.; Moio, L. Partial dealcoholization of red wines by membrane contactor technique: Effect on sensory characteristics and volatile composition. Food Bioprocess Technol. 2013, 6, 2289-2305. [CrossRef] 
30. Motta, S.; Guaita, M.; Petrozziello, M.; Ciambotti, A.; Panero, L.; Solomita, M.; Bosso, A. Comparison of the physicochemical and volatile composition of wine fractions obtained by two different dealcoholization techniques. Food Chem. 2017, 221, 1-10. [CrossRef] [PubMed]

31. Gambuti, A.; Rinaldi, A.; Lisanti, M.T.; Pessina, R.; Moio, L. Partial dealcoholisation of red wines by membrane contactor technique: Influence on colour, phenolic compounds and saliva precipitation index. Eur. Food Res. Technol. 2011, 233, 647. [CrossRef]

32. Gil, M.; Estévez, S.; Kontoudakis, N.; Fort, F.; Canals, J.; Zamora, F. Influence of partial dealcoholization by reverse osmosis on red wine composition and sensory characteristics. Eur. Food Res. Technol. 2013, 237, 481-488. [CrossRef]

33. Dai, J.; Mumper, R.J. Plant phenolics: Extraction, analysis and their antioxidant and anticancer properties. Molecules 2010, 15, 7313-7352. [CrossRef] [PubMed]

34. Simpson, R.F. Volatile aroma components of australian port wines. J. Sci. Food Agric. 1980, 31, $214-222$. [CrossRef]

35. Mayson, R. Port and the Douro; Infinite Ideas: Oxford, UK, 2012.

36. Lund, S.T.; Bohlmann, J. The molecular basis for wine grape quality-a volatile subject. Science 2006, 311, 804-805. [CrossRef] [PubMed]

(C) 2017 by the authors. Licensee MDPI, Basel, Switzerland. This article is an open access article distributed under the terms and conditions of the Creative Commons Attribution (CC BY) license (http:/ / creativecommons.org/licenses/by/4.0/). 